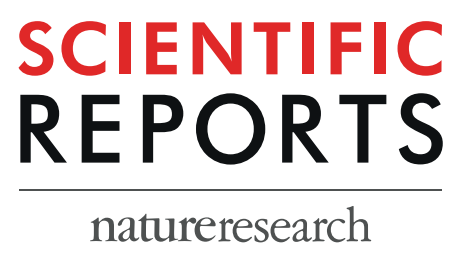

\title{
OPEN Association of alcohol dehydrogenase and aldehyde dehydrogenase Polymorphism with Spontaneous Deep Intracerebral Haemorrhage in the Taiwan population
}

\begin{abstract}
Yu-Hua Huang ${ }^{1}$, Kuo-Hsuan Chang ${ }^{1}$, Yun-Shien Lee ${ }^{2,3}$, Chiung-Mei Chen ${ }^{1}$ \& Yi-Chun Chen ${ }^{1 *}$
Alcohol dehydrogenase $(A D H)$ and aldehyde dehydrogenase $(A L D H)$ encode essential alcoholmetabolizing enzymes. While alcohol use is associated with spontaneously deep intracerebral haemorrhage (SDICH), particularly in males, the activities and genetic variants of $A D H$ and $A L D H$ may affect SDICH development. This case-control study was conducted to identify the interaction of alcohol use and SDICH with five single-nucleotide polymorphisms (SNPs): $A D H 1 B$ rs1229984, $A D H 1 C$ rs2241894, ALDH2 rs671, ALDH2 rs886205, and ALDH2 rs4648328. We enrolled 208 patients with SDICH and 244 healthy controls in a Taiwanese population. $A L D H 2$ rs 671 was significantly associated with SDICH in the dominant $(P<0.001)$ and additive models $(P=0.007)$. ALDH2 rs4648328 was borderline significantly associated with SDICH in the recessive $(P=0.024)$ or additive models $(P=0.030)$. In alcohol-using patients, the $A L D H 2$ rs $671 \mathrm{GG}$ genotype was associated with SDICH risk compared to the GA+AA genotype $(P=0.010)$. ADH1B rs1229984, $A D H 1 C$ rs2241894, and $A L D H 2$ rs886205 did not demonstrate association with SDICH. Thus, the $A L D H 2$ rs $671 \mathrm{GG}$ genotype is a risk factor for SDICH. Because the genetic distributions of $A L D H 2$ rs 671 exhibited strong ethnic heterogeneity, further studies in different populations are needed to validate these findings.
\end{abstract}

Primary intracerebral haemorrhage (ICH), accounting for 22-35\% of all cases of stroke in Asian populations ${ }^{1}$, is the most devastating stroke subtype with high rates of death and long-term disability in adults ${ }^{2,3}$. Asian populations have higher incidences of primary ICH than Caucasians ${ }^{2}$. Sixty to eighty percent of primary ICH cases occur at the non-lobar region, including the basal ganglia, thalamus, brain stem, and cerebellum, and are also known as spontaneously deep intracerebral haemorrhage $(\mathrm{SDICH})^{4}$. Numerous factors, such as hypertension and alcohol use, have been proposed to contribute to SDICH development ${ }^{5,6}$.

Alcohol use was associated with an increased ICH risk ${ }^{7}$. Alcohol is primarily metabolized by alcohol dehydrogenase $(\mathrm{ADH})$ and aldehyde dehydrogenase $(A L D H)^{8}$. The metabolism of alcohol produces acetaldehyde, acetate, and reactive oxygen species (ROS). Excessively produced acetaldehyde and ROS, which are highly reactive and toxic by-products, are distributed throughout cell membranes and interact with certain proteins, affecting cell function and leading to organs damage. The accumulation of acetaldehyde causes oxidative damage, excessive autophagy, decreased myofilament calcium sensitivity, and impaired endoplasmic reticulum calcium-ATPase function ${ }^{9}$. Acetate metabolism involved in lipid biosynthesis in the mitochondria of brain tissues ${ }^{10}$. In animal models, toxic aldehydes enlarged the cerebral ischaemia-induced infarct area and increased oxidative stress ${ }^{11,12}$. Deceased enzymatic activity of ALDH, a condition which impairs the degradation of acetaldehyde, could be

${ }^{1}$ Department of Neurology, Chang Gung Memorial Hospital Linkou Medical Center and College of Medicine, ChangGung University, Taoyuan, 333, Taiwan. '2Department of Biotechnology, Ming Chuan University, Taoyuan, 333, Taiwan. ${ }^{3}$ Genomic Medicine Research Core Laboratory, Chang Gung Memorial Hospital, Taoyuan, 333, Taiwan.

*email: asd108@adm.cgmh.org.tw 


\begin{tabular}{|c|c|c|c|c|c|c|c|c|c|}
\hline & \multicolumn{2}{|c|}{ All $(\mathrm{N}=452)$} & \multirow[b]{3}{*}{$P$-Value } & \multicolumn{2}{|c|}{ Male $(\mathrm{N}=269)$} & \multirow[b]{3}{*}{$P$-Value } & \multicolumn{2}{|c|}{ Female $(\mathrm{N}=183)$} & \multirow[b]{3}{*}{$P$-Value } \\
\hline & \multirow{2}{*}{\begin{tabular}{|l|} 
SDICH \\
$(\mathrm{N}=208)$ \\
\end{tabular}} & \multirow{2}{*}{\begin{tabular}{|l|} 
Control \\
$(\mathrm{N}=\mathbf{2 4 4})$ \\
\end{tabular}} & & \multirow{2}{*}{\begin{tabular}{|l|} 
SDICH \\
$(\mathrm{N}=141)$ \\
\end{tabular}} & \multirow{2}{*}{$\begin{array}{l}\text { Control } \\
(\mathrm{N}=128)\end{array}$} & & \multirow{2}{*}{\begin{tabular}{|l|} 
SDICH \\
$(\mathrm{N}=67)$ \\
\end{tabular}} & \multirow{2}{*}{\begin{tabular}{|l|} 
Control \\
$(\mathrm{N}=116)$ \\
\end{tabular}} & \\
\hline & & & & & & & & & \\
\hline Age (years) & $57.4 \pm 10.5$ & $60.0 \pm 10.5$ & 0.012 & $55.3 \pm 10.2$ & $59.5 \pm 10.6$ & 0.002 & $61.9 \pm 9.9$ & $60.5 \pm 10.5$ & 0.378 \\
\hline Male gender & $141(67.8 \%)$ & $128(52.5 \%)$ & 0.001 & & & & & & \\
\hline Hypertension & $187(89.9 \%)$ & $103(42.4 \%)$ & $<0.001$ & $125(88.7 \%)$ & $57(44.8 \%)$ & $<0.001$ & $62(92.5 \%)$ & $46(39.6 \%)$ & $<0.001$ \\
\hline Diabetes mellitus & $39(18.8 \%)$ & $41(16.9 \%)$ & 0.602 & $22(15.6 \%)$ & $21(16.5 \%)$ & 0.835 & $17(25.4 \%)$ & $20(17.2 \%)$ & 0.189 \\
\hline Alcohol use & $67(32.2 \%)$ & $36(14.8 \%)$ & $<0.001$ & $65(46.1 \%)$ & $33(26.0 \%)$ & 0.001 & $2(3 \%)$ & $3(2.6 \%)$ & 0.873 \\
\hline Smoke & $92(44.2 \%)$ & $47(19.3 \%)$ & $<0.001$ & $90(63.8 \%)$ & $45(35.4 \%)$ & $<0.001$ & $2(3 \%)$ & $2(1.7 \%)$ & 0.579 \\
\hline $\begin{array}{l}\text { Total cholesterol } \\
(\mathrm{mg} / \mathrm{dL})\end{array}$ & $184.6 \pm 38.9$ & $200.2 \pm 42.9$ & 0.001 & $184.0 \pm 35.2$ & $193.8 \pm 46.6$ & 0.076 & $185.9 \pm 46.0$ & $208.3 \pm 36.4$ & 0.003 \\
\hline
\end{tabular}

Table 1. Demographic data of the study population. Data are expressed as number, percentage, or mean \pm SD. Comparisons between controls and ICH group were analysed by Chi-square test or $t$-test where appropriate.

associated with higher alcohol intoxication among East Asians compared to Caucasians ${ }^{13}$. Previous studies suggested an association between genetic variants in the alcohol metabolism pathway and vascular diseases ${ }^{14}$. Individuals with the $A L D H 2$ rs671 A allele have higher prevalence of hypertension, cardiovascular risk factors, and cerebral infarction ${ }^{15}$. Polymorphisms in $A L D H 2$ rs671 are associated with coronary artery disease (CAD) in Chinese patients with hypertension ${ }^{16}$. In the male Japanese population, the $A L D H 2$ rs671 GG genotype is associated with cerebral lacunar infarcts ${ }^{17}$. In contrast, presence of the $A L D H 2$ rs671 A allele could be a risk factor for cerebral infarction in Han-Chinese population ${ }^{15}$. A reduction in ALDH2 activity may interfere with endothelium angiogenesis and is associated with cerebral amyloid angiopathy ${ }^{18}$.

However, the association between the genetic variants involved in alcohol metabolism and SDICH remains unclear. Here, we conducted a case-control study to investigate the associations of genetic variants in $A D H$ and $A L D H$, including $A D H 1 B$ rs1229984, $A D H 1 C$ rs2241894, $A L D H 2$ rs671, $A L D H 2$ rs886205, and $A L D H 2$ rs4648328, and SDICH in a Taiwanese population.

\section{Results}

Patient characteristics. Among the 208 cases with SDICH and 244 controls, the percentage of men (67.8\%) and those with hypertension (89.9\%) were significantly higher in the SDICH group compared to in control group (men: $52.5 \%, P=0.001$; hypertension: $42.4 \%, P<0.001$, Table 1 ). More patients with SDICH had were exposed to alcohol (32.2\%) or smoking (44.2\%) compared to controls (alcohol use: $14.8 \%, P<0.001$; smoking: $19.3 \%$, $P<0.001)$. The levels of total cholesterol $(184.6 \pm 38.9 \mathrm{mg} / \mathrm{dL})$ in patients with SDICH were lower compared to in controls (total cholesterol: $200.2 \pm 42.9 \mathrm{mg} / \mathrm{dL}, P=0.001$ ). Alcohol use (SDICH vs controls: $46.1 \%$ vs $26.0 \%$, $P=0.001$ ) and smoking (SDICH vs controls: $63.8 \%$ vs $35.4 \%, P<0.001$ ) were more frequently observed in the male patients with SDICH (Table 1).

Genotype frequency and association analysis of controls and patients with SDICH. All single-nucleotide polymorphisms (SNPs) were in Hardy-Weinberg equilibrium in the case and control groups according to the standard $\chi^{2}$ test at a significance level of 0.05 . The genotype frequencies of the analysed SNPs in the case and control groups are shown in Table 2. ALDH2 rs671 was significantly associated with SDICH in the dominant model ( $\mathrm{OR}=0.5,95 \% \mathrm{CI}: 0.4-0.8, P<0.001)$ and additive model $(\mathrm{OR}=0.7,95 \% \mathrm{CI}: 0.5-0.9$, $P=0.007)$. The significance remained after adjusting for sex and age in the dominant model $(\mathrm{OR}=0.6,95 \% \mathrm{CI}$ : $0.4-0.8, P=0.003)$ and borderline in the additive model $(\mathrm{OR}=1.5,95 \% \mathrm{CI}: 1.1-2.0, P=0.015)$. However, these associations did not remain after further adjusting for hypertension and alcohol use. ALDH2 rs4648328 could be associated with SDICH in the recessive model ( $\mathrm{OR}=2.4,95 \% \mathrm{CI}: 1.1-5.1, P=0.024)$ and additive model $(\mathrm{OR}=1.4,95 \% \mathrm{CI}: 1.0-1.9, P=0.030)$ with boardline significance. These associations were not detected after Bonferroni correction and multivariate adjustment. The genotypic frequencies of other genetic variants were similar between the SDICH and controls.

The minor allele frequencies (MAFs) of the analysed SNPs in the case and control groups are shown in Table 3. The MAF of ALDH2 rs671 (21.9\%) in the SDICH group was significantly lower compared to controls $(30.1 \%$, odds ratio $(\mathrm{OR})=0.7,95 \%$ confidence interval $(\mathrm{CI}): 0.5-0.9, P=0.005)$. The MAFs of the other SNPs were similar between the SDICH and control groups.

We further stratified the allelic and genotypic frequencies of $A D H 1 B$ rs1229984, ADH1C rs2241894, ALDH2 rs671, ALDH2 rs886205, and ALDH2 rs4648328 according to alcohol use. When stratified by alcohol use, the $A L D H 2$ rs671 GA genotype was significantly associated with SDICH in the alcohol use group (OR $=0.2,95 \% \mathrm{CI}$ : $0.1-0.7, P=0.008$ ), indicating the interaction between the $A L D H 2$ rs671 genotype and alcohol use. Specifically, in alcohol-free subjects, the SDICH risk was similar between genotypes. In subjects with alcohol use, SDICH was more frequently observed in individuals carrying $A L D H 2$ rs671 GG genotype compared to rs671 GA+AA genotype (SDICH percentage: GG vs GA+AA: $70.6 \%$ vs $38.9 \%$, OR $=0.3,95 \%$ CI $0.1-0.8$, crude $P=0.01$, Fig. 1), whereas this difference was not observed after multivariable adjustment. There was no association between all tested SNPs and SDICH by stratification according to the presences of hypertension and gender (data not shown). None of the alleles and genotypes in this study showed associations with hypertension (Supplementary Table S1).

We further characterized the $A L D H 2$ SNPs by linkage disequilibrium (LD) and haplotype analyses. LD analysis showed that rs4648328 and rs671 were highly correlated with each other (Fig. 2). Haplotype 


\begin{tabular}{|c|c|c|c|c|c|c|c|}
\hline \multirow[b]{2}{*}{ Gene } & \multirow[b]{2}{*}{ SNP ID } & \multirow[b]{2}{*}{ Genotype } & \multirow[b]{2}{*}{ SDICH (\%) } & \multirow[b]{2}{*}{ Control (\%) } & \multirow{2}{*}{$\begin{array}{l}\text { Model } 1 \\
\text { OR }(95 \% \text { CI }), P \text { value } \\
\end{array}$} & \multirow{2}{*}{$\begin{array}{l}\text { Model } 2 \\
\text { OR }(95 \% \text { CI }), P \text { value } \\
\end{array}$} & \multirow{2}{*}{$\begin{array}{l}\text { Model } 3 \\
P \text { value }\end{array}$} \\
\hline & & & & & & & \\
\hline \multirow{18}{*}{ ALDH2 } & \multirow{6}{*}{ rs671 } & GG & $133(63.9)$ & $118(48.4)$ & & & \\
\hline & & GA & $59(28.4)$ & $105(43.0)$ & & & \\
\hline & & $\mathrm{AA}$ & $16(7.7)$ & $21(8.6)$ & & & \\
\hline & & Dominant model & & & $0.5(0.4-0.8),<0.001$ & $0.6(0.4-0.8), 0.003$ & 0.231 \\
\hline & & Additive model & & & $0.7(0.5-0.9), 0.007$ & $1.5(1.1-2.0), 0.015$ & 0.528 \\
\hline & & Recessive model & & & 0.724 & 0.685 & 0.496 \\
\hline & \multirow{6}{*}{ rs4648328 } & $\mathrm{CC}$ & $111(53.4)$ & $148(60.6)$ & & & \\
\hline & & $\mathrm{CT}$ & $76(36.5)$ & $85(34.8)$ & & & \\
\hline & & TT & $21(10.1)$ & $11(4.5)$ & & & \\
\hline & & Dominant model & & & 0.119 & 0.221 & 0.725 \\
\hline & & Additive model & & & $1.4(1.0-1.9), 0.030$ & 0.072 & 0.552 \\
\hline & & Recessive model & & & $2.4(1.1-5.1), 0.024$ & 0.046 & 0.448 \\
\hline & \multirow{6}{*}{ rs886205 } & GG & $154(74.0)$ & $179(73.4)$ & & & \\
\hline & & GA & $52(25.0)$ & $59(24.2)$ & & & \\
\hline & & AA & $2(1.0)$ & $6(2.4)$ & & & \\
\hline & & Dominant model & & & 0.871 & 0.852 & 0.777 \\
\hline & & Additive model & & & 0.636 & 0.617 & 0.524 \\
\hline & & Recessive model & & & 0.246 & 0.237 & 0.173 \\
\hline \multirow{12}{*}{$\mathrm{ADH}$} & \multirow{6}{*}{ rs1229984 } & TT & $112(53.8)$ & $129(52.9)$ & & & \\
\hline & & TC & $80(38.5)$ & $105(43.0)$ & & & \\
\hline & & CC & $16(7.7)$ & $10(4.1)$ & & & \\
\hline & & Dominant model & & & 0.836 & 0.816 & 0.817 \\
\hline & & Additive model & & & 0.646 & 0.662 & 0.607 \\
\hline & & Recessive model & & & 0.107 & 0.107 & 0.075 \\
\hline & \multirow{6}{*}{ rs2241894 } & $\mathrm{CC}$ & $103(49.5)$ & $125(51.2)$ & & & \\
\hline & & $\mathrm{CT}$ & $92(44.2)$ & $101(41.4)$ & & & \\
\hline & & TT & $13(6.3)$ & $18(7.4)$ & & & \\
\hline & & Dominant model & & & 0.717 & 0.724 & 0.376 \\
\hline & & Additive model & & & 0.920 & 0.896 & 0.347 \\
\hline & & Recessive model & & & 0.637 & 0.701 & 0.589 \\
\hline
\end{tabular}

Table 2. Genotypes of the SNPs and their associations with risk of spontaneously deep intracerebral haemorrhage (SDICH). SDICH: spontaneous deep intracerebral haemorrhage, OR: Odds ratio, CI: confidence interval. Analysis were performed by logistic regression under dominant, additive and recessive genetic models. Model 1: Crude logistic regression. Model 2: Multivariable logistic regression, adjust sex, age. Model 3: Multivariable logistic regression, adjust sex, age, HTN and alcohol. $P$-value with Bonferroni correction for significance was 0.01 .

analysis demonstrated that the haplotype "GT" of rs671-rs4648328 was associated with SDICH $(\mathrm{OR}=1.4 ; 95 \%$ CI: 1.0 1.8, $P=0.047$, Table 4$)$. In contrast, haplotype "AC" demonstrated protective effect on SDICH $(\mathrm{OR}=0.6$; 95\% CI: 0.5 0.9, $P=0.005)$.

\section{Discussion}

This study, at the first time, describes the potential association between SNPs of ADH and ALDH2 with SDICH susceptibility in the Taiwanese population. Asian populations have higher incidences of SDICH with high mortality and long-term disability than Caucasians ${ }^{2,3,19}$. Alcohol use demonstrates the association with $\mathrm{SDICH}^{7}$. Alcohol is primarily metabolized by $\mathrm{ADH}$ and $\mathrm{ALDH}^{8}$. Our results support a role for $A L D H 2$ genetic variants in SDICH. We found that the $A L D H 2$ rs671 GG genotype could be a risk locus for SDICH, particularly in subjects who used alcohol, in Taiwanese population. Haplotype analysis further identified the association between haplotypes in rs671-rs4648328 of ALDH2 and SDICH. Further large case-control cohorts in multi-ethnicities are needed to validate this association.

The rs671 is a functional SNP (Glu504Lys) in $A L D H 2^{20}$. Minor allele (A allele) of rs671 results in reduced ALDH2 enzymatic activity. Approximately $30 \%$ of people in Asia and $47 \%$ of those in Taiwan carrying the rs 671 A allele $e^{21-24}$. In the male Japanese population, the $A L D H 2$ rs671 GG genotype is associated with cerebral lacunar infarcts ${ }^{17}$. ALDH2 rs671 A allele are associated with coronary artery disease in Chinese patients with hypertension $^{16}$. Moreover, $A L D H 2$ rs671 A allele is also associated with hypertension and cerebral amyloid angiopathy ${ }^{18,25}$. Although $A L D H$ rs671 AA genotype may be associated with alcoholism-related hypertension ${ }^{26}$, our results did not detect the association between $A L D H 2$ rs671 and hypertension, supporting the primary effect of $A L D H 2$ rs671 on SDICH. ALDH2 rs671 GG genotype tends to be a risk factor for SDICH, particularly in the group with alcohol use in Taiwanese. 


\begin{tabular}{|c|c|c|c|c|c|c|c|}
\hline \multirow[b]{2}{*}{ Gene } & \multirow[b]{2}{*}{ SNP ID } & \multirow[b]{2}{*}{ All cases MAF } & \multicolumn{2}{|l|}{ MAF } & \multirow{2}{*}{\begin{tabular}{|l|} 
Model 1 \\
OR (95\% CI), P value \\
\end{tabular}} & \multirow{2}{*}{\begin{tabular}{|l|} 
Model 2 \\
$P$ value
\end{tabular}} & \multirow{2}{*}{$\begin{array}{l}\text { Model } 3 \\
P \text { value }\end{array}$} \\
\hline & & & SDICH (\%) & Control (\%) & & & \\
\hline \multirow{3}{*}{ ALDH2 } & rs671 & $\mathrm{A} / 0.263$ & 0.219 & 0.301 & $0.7(0.5-0.9), 0.005$ & 0.012 & 0.523 \\
\hline & rs4648328 & $\mathrm{T} / 0.249$ & 0.284 & 0.219 & $1.4(1.0-1.9), 0.026$ & 0.065 & 0.543 \\
\hline & rs886205 & $\mathrm{A} / 0.141$ & 0.135 & 0.146 & 0.640 & 0.620 & 0.528 \\
\hline \multirow{2}{*}{$\mathrm{ADH}$} & rs1229984 & $\mathrm{C} / 0.262$ & 0.269 & 0.256 & 0.655 & 0.671 & 0.617 \\
\hline & rs2241894 & $\mathrm{T} / 0.282$ & 0.284 & 0.281 & 0.923 & 0.899 & 0.365 \\
\hline
\end{tabular}

Table 3. Allele frequencies of SNPs and their associations with risk of spontaneously deep intracerebral haemorrhage (SDICH). SDICH: spontaneous deep intracerebral haemorrhage, OR: Odds ratio, CI: confidence interval, MAF: minor allele frequency. Analysis was performed by logistic regression. Model 1: Crude logistic regression. Model 2: Multivariable logistic regression, adjust sex, age. Model 3: Multivariable logistic regression, adjust sex, age, HTN, and alcohol. $P$-value with Bonferroni correction for significance was 0.01 .

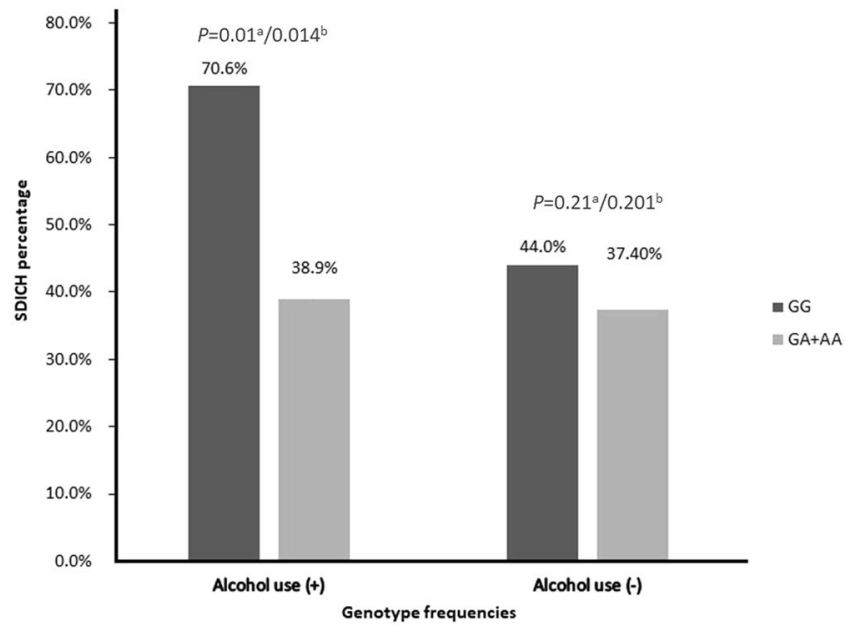

Figure 1. Interaction between $A L D H 2$ rs671 genotype and alcohol use to SDICH susceptibility. Comparisons between controls and ICH group were analysed by logistic regression under alcohol use or not. Although the interactive effect between alcohol use and rs671 genotype was borderline significant $(P=0.07)$, in those with alcohol use, the $A L D H 2$ rs671 GG genotype was a significant risk for SDICH compared to the rs671 GA+AA genotype (SDICH percentage: GG vs GA+AA: $70.6 \%$ vs $38.9 \%, \mathrm{OR}=0.3,95 \% \mathrm{CI} 0.1-0.8, P=0.01^{\mathrm{a}}$ ) and borderline significance $\left(P=0.014^{\mathrm{b}}\right)$ while adjusting for sex and age. In contrast, the SDICH risk was similar between genotypes $\left(P=0.21^{\mathrm{a}}\right.$ and $\left.P=0.201^{\mathrm{b}}\right)$ in alcohol-free subjects. ${ }^{\mathrm{a} C r u d e}$ logistic regression. ${ }^{\mathrm{b}}$ Multivariable logistic regression, adjust for sex and age.

$A L D H 2$ rs4648328, an intronic SNP, was associated with delayed alcohol metabolism in European population ${ }^{27}$. In our analysis, we found a potential association between rs4648328 and SDICH in the recessive and additive models. SNPs in ALDH2 demonstrated strong LD in Indian population ${ }^{27}$. In addition, our study showed that rs4648328 was in LD with rs671 in Taiwanese population. The haplotype "GT" of ALDH2 rs671-rs4648328 was associated with SDICH, whereas the haplotype "AC" demonstrated protective effect on SDICH. This study provides a baseline for future research about the role of the $A L D H 2$ loci in SDICH in Taiwanese population. Further large-scale investigations are needed to confirm this result.

Table 5 shows ethnicity differences in SNPs of ADH and ALDH. The genetic distributions of ALDH2 rs671 showed strong ethnic heterogeneity. The frequencies of A allele in Taiwanese (26.3\%) and East Asians (17.4\%) are much higher compared to Americans (0\%), Europeans (0\%) and global populations (3,6\%). Previous studies showed that genetic variants of $A L D H 2$ rs671 were associated with both alcohol flushing and alcohol use in Asian populations ${ }^{28,29}$. Additionally, the $A L D H 2$ rs671 GG genotype is associated with cerebral lacunar infarcts in the male Japanese ${ }^{17}$. Our study showed that rs671 GG genotype was associated with SDICH susceptibility, particularly in the alcohol use group.

In addition to rs671, the MAFs of rs886205, rs1229984, and rs2241894 also greatly differ between Asian and Caucasians ${ }^{30}$. Table 5 showed the ethnic heterogeneous of the rs671, rs886205 rs1229984, and rs2241894 according to 1000 genome information.

The MAF T allele was present in $15.9 \%$ of rs 1229984 in global population, while the rs $1229984 \mathrm{C}$ allele was present in $26.2 \%$ of Taiwanese and $30.3 \%$ of east Asian. (Table 5). While the ADH1B 1229984 CC genotype is predominant in East Asian population, it is rarely observed in Indian population ${ }^{31}$. The role of $A D H 1 B$ rs 1229984 in modulating alcohol consumption remains controversial. It has been reported that $A D H 1 B$ rs $1229984 \mathrm{C}$ allele is associated with alcoholism31. However, a case-control study suggests that CC genotype of ADH1B rs1229984 may protect against alcohol dependence ${ }^{32}$. In our analysis, the $A D H 1 B$ rs1229984 did not demonstrate association with alcohol consumption. 

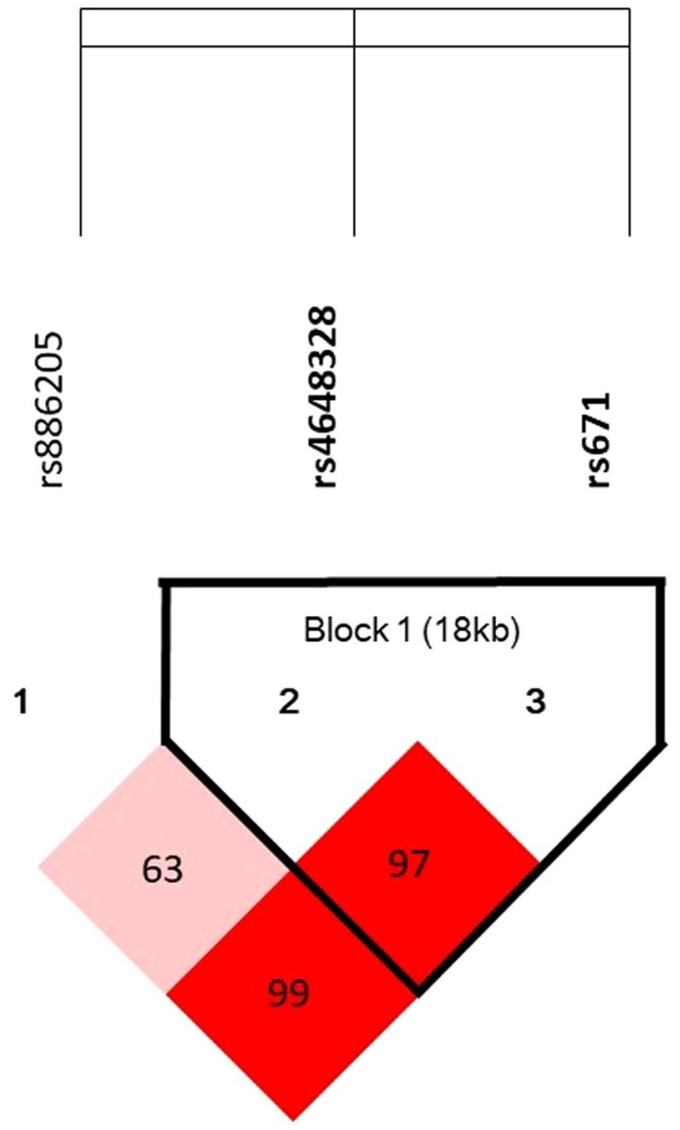

Figure 2. Linkage disequilibrium (LD) between the SNP markers in ALDH2 in the Taiwanese population. Graphical representation of SNPs in Haploview linkage disequilibrium (LD) of $A L D H 2$ gene in SDICH patients and controls. Haploview LD coefficients $\mathrm{D}^{\prime} \times 100$ were generated by Haploview 4.2 and shown in each cell using the standard color scheme. $\mathrm{D}^{\prime}$ values of " 0 " indicates the independence of the examined two loci while a value of " 1 " demonstrates complete linkage. The strength of LD is depicted by red intensity, which moves from white to red as $\mathrm{D}^{\prime} \times 100$ progresses from 1 to 100. Two SNPs (rs671 and rs4648328) constitute one haplotype block that span $18 \mathrm{~kb}$ of ALDH2 gene with strong linkage disequilibrium (LD), shown in bright red $\left(\mathrm{D}^{\prime}: 0.97 ; \mathrm{r}^{2}: 0.11\right)$. The $\mathrm{LD}$ values were presented as $\mathrm{D}^{\prime}: 0.99\left(\mathrm{r}^{2}: 0.05\right)$ between $\mathrm{rs} 671 \&$ rs886205 and $\mathrm{D}^{\prime}: 0.63\left(\mathrm{r}^{2}: 0.02\right)$ between rs4648328 \& rs886205 respectively.

\begin{tabular}{|l|l|l|l|l|l|l|}
\hline & rs671 & rs4648328 & Case (freq\%) & Control(freq\%) & OR (95\% CI) & Fischer's P \\
\hline Genotypes & GG/GA/AA & CC/CT/TT & & & & \\
\hline Haplotype & & & & & & \\
\hline Hap1 & A & C & 21.5 & 29.8 & $0.6(0.5 \sim 0.9)$ & 0.005 \\
\hline Hap2 & G & T & 28.0 & 22.4 & $1.4(1.0 \sim 1.8)$ & 0.047 \\
\hline Hap3 & G & C & 50.1 & 47.8 & $1.1(0.9 \sim 1.4)$ & 0.452 \\
\hline
\end{tabular}

Table 4. The association between haplotypes of $A L D H 2$ genetic polymorphisms and the risk of spontaneously deep intracerebral hemorrhage (SDICH). ALDH, aldehyde dehydrogenase; CI, confidence interval; Hap, haplotype; OR, odds ratio.

The MAF C allele was present in $47.2 \%$ of rs2241894 in global population, while the rs2241894 T allele was present in $28.2 \%$ of Taiwanese. A genome-wide association study also demonstrated an association between ADH1C rs2241894 and alcohol dependence in African and European Americans ${ }^{14}$. The MAF A allele was present in $49.1 \%$ of rs886205 in global population, while the rs886205 A allele was present in $14.1 \%$ of Taiwanese. A recent study reported that $A L D H 2$ rs886205 is associated with alcohol-dependent patients ${ }^{33}$. However, we found no associations between $A L D H 2$ rs886205, ADH1C rs2241894, alcohol use and SDICH in our analysis. This discrepancy may be contributed by the ethnic difference of genetic background, as well as the design of studies.

To our knowledge, this is the first study to propose that the $A L D H 2$ rs671 GG genotype is a risk factor for SDICH, particularly in an alcohol-using population. $A L D H 2$ rs671 and rs4648328 are particularly important in the interaction with alcohol use, one of the major environmental risk factors for SDICH. There are limitations to our study. First, this was a hospital-based study which may limit the generalization of our results to the whole population. Most 


\begin{tabular}{|c|c|c|c|c|c|c|c|c|}
\hline \multirow{3}{*}{$\begin{array}{l}\text { Gene } \\
\text { Sample size }\end{array}$} & \multirow{3}{*}{ SNP ID } & \multicolumn{7}{|l|}{ MAF } \\
\hline & & Present study & Global $^{a}$ & East Asian $^{a}$ & South Asian ${ }^{\mathrm{a}}$ & American $^{\mathrm{a}}$ & Europe $^{\mathrm{a}}$ & Africa $^{a}$ \\
\hline & & $\mathrm{N}=452$ & $\mathrm{~N}=5008$ & $\mathrm{~N}=1008$ & $\mathrm{~N}=987$ & $\mathrm{~N}=694$ & $\mathrm{~N}=1006$ & $\mathrm{~N}=1322$ \\
\hline \multirow{3}{*}{ ALDH2 } & rs671 & A/0.263 & $\mathrm{A} / 0.036$ & $\mathrm{~A} / 0.174$ & $\mathrm{~A} / 0.000$ & $\mathrm{~A} / 0.000$ & $\mathrm{~A} / 0.000$ & $\mathrm{~A} / 0.002$ \\
\hline & \begin{tabular}{|l|} 
rs4648328 \\
\end{tabular} & $\mathrm{T} / 0.249$ & $\mathrm{~T} / 0.200$ & $\mathrm{~T} / 0.263$ & $\mathrm{~T} / 0.210$ & $\mathrm{~T} / 0.150$ & $\mathrm{~T} / 0.159$ & $\mathrm{~T} / 0.204$ \\
\hline & \begin{tabular}{|l|} 
rs886205 \\
\end{tabular} & A/0.141 & $\mathrm{A} / 0.491$ & A/0.156 & G/0.290 & $\mathrm{G} / 0.310$ & G/0.166 & $\mathrm{A} / 0.223$ \\
\hline \multirow{2}{*}{$\mathrm{ADH}$} & \begin{tabular}{|l|} 
rs1229984 \\
\end{tabular} & $\mathrm{C} / 0.262$ & $\mathrm{~T} / 0.159$ & $\mathrm{C} / 0.303$ & $\mathrm{~T} / 0.020$ & $\mathrm{~T} / 0.060$ & $\mathrm{~T} / 0.029$ & $\mathrm{~T} / 0.002$ \\
\hline & rs2241894 & $\mathrm{T} / 0.282$ & $\mathrm{C} / 0.472$ & $\mathrm{~T} / 0.236$ & $\mathrm{~T} / 0.400$ & $\mathrm{C} / 0.170$ & $\mathrm{C} / 0.231$ & $\mathrm{C} / 0.495$ \\
\hline
\end{tabular}

Table 5. Minor allele frequency (MAF) in different populations. SNP: Single-nucleotide polymorphism; MAF: minor allele frequency. ${ }^{\mathrm{a}} \mathrm{MAF}$ data from 1000 genome information.

of patients with SDICH were recruited from the Department of Neurology; these patients may demonstrate smaller haemorrhages compared to those admitted to the Department of Neurosurgery. Additionally, the relatively small sample size and gender imbalance may limit detection of potential genetic associations with SDICH. However, our results support the potential association of genetic variants in $A L D H 2$ rs671 GG genotype with SDICH risk in a Taiwanese population. Further studies in different populations are needed to validate our results.

Conclusion. This study revealed a significant association between the genetic variants of $A L D H 2$ and SDICH susceptibility. Carrying the $A L D H 2$ rs671 GG genotype tends to be a risk factor for SDICH, particularly in those who use alcohol.

\section{Materials and Methods}

Patients and control subjects. Patients (age $>30$ years old) with SDICH at the basal ganglia, thalamus, cerebellum, or brainstem were included in the study ${ }^{4}$. The size and location of SDICH were confirmed by brain computed tomography (CT). Patients with traumatic cerebral haemorrhage, haemorrhagic transformation of a cerebral infarct, vascular anomaly, and secondary intracranial haemorrhage (coagulopathy or hyper-perfusion syndrome) were excluded. Controls were defined as those without medical disease such as renal failure, myocardial infarction, cancer, stroke history, and neurodegenerative disease. A history of hypertension, diabetes mellitus, smoking, alcohol use, and lipid profile were collected from all participants. Alcohol use referred to the consumption of greater than $210 \mathrm{~g}$ of alcohol per week ${ }^{34}$. Smokers were defined as former or current smokers ${ }^{35}$.

This retrospective case-control study was approved by the Chang Gung Memorial Hospital Institution Ethics Review Board for human studies, and patients provided written informed consent prior to study participation (IRB201600775B0). All methods were performed in accordance with the relevant guidelines and regulations.

Selection of SNP and genotyping. The cytogenetic location of $A L D H 2$ is $12 \mathrm{q} 24$. In the literature review, approximately $30 \%$ people in Asia and $47 \%$ in Taiwan were described to carry genetic variants of the A allele in $A L D H 2$ with reduced enzymatic activity ${ }^{21-23}$. We selected the $A L H D 2$ rs671 (G $>$ A, missense variant Glu504Lys, exon 12), $A L D H 2$ rs4648328 (C > T, intron variant, intron 3), and $A L D H 2$ rs886205 (G > A, promoter, $5^{\prime}$-untranslated region) based on previous evidence of its association with alcohol dependence ${ }^{26,31}$. For $A D H$ (cytogenetic location at 4q22), we selected $A D H 1 B$ rs1229984 (T > C, missense variant Arg48His, exon 3) and ADH1C rs2241894 (A > G, synonymous variant Thr151, exon 5). ADH1B rs1229984 was previously investigated for its association with alcohol metabolism and alcohol drinking behaviours ${ }^{32}$. Additionally, ADH1B rs1229984, $A D H 1 C$ rs2241894, and ALDH2 rs671 are greatly different between Asians and Caucasians (Table 5) ${ }^{30}$.

Blood samples were collected for genotyping. The genomic DNA was extracted from peripheral leukocytes by using the Stratagene DNA extraction kit (La Jolla, CA, USA). Polymorphisms were genotyped using TaqMan SNP Assays in the ABI Prism 7900HT Sequence Detection System (Applied Biosystems, Foster City, CA, USA). The primer sets used for polymerase chain reaction amplification of each SNP region are as listed in Supplementary Table S2. Each SNP was checked for Hardy-Weinberg equilibrium using the standard $\chi^{2}$ test at a significance level of 0.05. Patterns of LD and haplotype analyses were evaluated using SHEsis Online Version (http://analysis.bio-x. $\mathrm{cn} /$ myAnalysis.php $)^{36}$. Haplotypes with frequency $<3 \%$ were excluded from association analysis.

Statistical analysis and power estimation. All data analyses were performed using SAS Software (version 9.4; SAS Institute, Cary, NC, USA). Demographic data and the distributions of genotypes of SNPs were analysed by $\chi^{2}$ test, $t$-test, and univariate logistic regression. Multivariable logistic regression analyses were used to test the null hypothesis that the number of cases and controls did not differ with various genotypes of the five SNPs. Potential covariables included age, sex, hypertension, total cholesterol level, and alcohol use. Samples were stratified by alcohol use using multivariable logistic regression. All $P$ values were two-tailed. While considering Bonferroni correction, the significance level was set to 0.01 . Given the observed allele frequency in the present case-control study, at the 0.01 significance level, we had power greater than 0.8 to identify an association of the genetic variant with SDICH susceptibility when the per-allele genetic effect was greater than an odds ratio of 1.8 for rs886205 and 1.7 for the rest of the SNPs.

Received: 25 July 2019; Accepted: 10 February 2020;

Published online: 27 February 2020 


\section{References}

1. Hsieh, F. I. et al. Get With the Guidelines-Stroke performance indicators: surveillance of stroke care in the Taiwan Stroke Registry: Get With the Guidelines-Stroke in Taiwan. Circulation 122, 1116-1123, https://doi.org/10.1161/circulationaha.110.936526 (2010).

2. Qureshi, A. I., Mendelow, A. D. \& Hanley, D. F. Intracerebral haemorrhage. Lancet 373, 1632-1644 (2009).

3. Flaherty, M. L. et al. Long-term mortality after intracerebral hemorrhage. Neurology 66, 1182-1186 (2006).

4. Qureshi, A. I. et al. Spontaneous intracerebral hemorrhage. N Engl J Med 344, 1450-1460, https://doi.org/10.1056/ nejm200105103441907 (2001).

5. Broderick, J. et al. Guidelines for the management of spontaneous intracerebral hemorrhage in adults: 2007 update: a guideline from the American Heart Association/American Stroke Association Stroke Council, High Blood Pressure Research Council, and the Quality of Care and Outcomes in Research Interdisciplinary Working Group. Stroke 38, 2001-2023, https://doi.org/10.1161/ strokeaha.107.183689 (2007).

6. Chen, C. J. et al. Alcohol use and risk of intracerebral hemorrhage. Neurology 88, 2043-2051, https://doi.org/10.1212/ wnl.0000000000003952 (2017).

7. O’Leary, M. J. Spontaneous intracerebral hemorrhage. N Engl J Med 345, 769; author reply 770 (2001).

8. Chen, C. H., Ferreira, J. C., Gross, E. R. \& Mochly-Rosen, D. Targeting aldehyde dehydrogenase 2: new therapeutic opportunities. Physiol Rev 94, 1-34, https://doi.org/10.1152/physrev.00017.2013 (2014).

9. Zhang, Y. \& Ren, J. ALDH2 in alcoholic heart diseases: molecular mechanism and clinical implications. Pharmacol Ther 132, 86-95, https://doi.org/10.1016/j.pharmthera.2011.05.008 (2011).

10. Zakhari, S. Overview: how is alcohol metabolized by the body? Alcohol Res Health 29, 245-254 (2006).

11. O’Brien, P. J., Siraki, A. G. \& Shangari, N. Aldehyde sources, metabolism, molecular toxicity mechanisms, and possible effects on human health. Crit Rev Toxicol 35, 609-662 (2005).

12. Lee, W. C. et al. Lipid peroxidation dysregulation in ischemic stroke: plasma 4-HNE as a potential biomarker? Biochem Biophys Res Commun 425, 842-847, https://doi.org/10.1016/j.bbrc.2012.08.002 (2012).

13. Impraim, C., Wang, G. \& Yoshida, A. Structural mutation in a major human aldehyde dehydrogenase gene results in loss of enzyme activity. Am J Hum Genet 34, 837-841 (1982).

14. Gelernter, J. et al. Genome-wide association study of alcohol dependence:significant findings in African- and European-Americans including novel risk loci. Mol Psychiatry 19, 41-49, https://doi.org/10.1038/mp.2013.145 (2014).

15. Xu, H., Zhang, Y. \& Ren, J. ALDH2 and Stroke: A Systematic Review of the Evidence. Adv Exp Med Biol 1193, 195-210, https://doi. org/10.1007/978-981-13-6260-6_11 (2019).

16. Wang, Y. et al. Synergistic association between two alcohol metabolism relevant genes and coronary artery disease among Chinese hypertensive patients. PloS one 9, e103161, https://doi.org/10.1371/journal.pone.0103161 (2014).

17. Nagasawa, H. et al. A polymorphism of the aldehyde dehydrogenase 2 gene is a risk factor for multiple lacunar infarcts in Japanese men: the Takahata Study. Eur J Neurol 14, 428-434, https://doi.org/10.1111/j.1468-1331.2007.01700.x (2007).

18. Solito, R. et al. Mitochondrial aldehyde dehydrogenase-2 activation prevents beta-amyloid-induced endothelial cell dysfunction and restores angiogenesis. J Cell Sci 126, 1952-1961, https://doi.org/10.1242/jcs.117184 (2013).

19. Hsieh, F. I. et al. Get With the Guidelines-Stroke performance indicators: surveillance of stroke care in the Taiwan Stroke Registry: Get With the Guidelines-Stroke in Taiwan. Circulation 122, 1116-1123 (2010).

20. Edenberg, H. J. The genetics of alcohol metabolism: role of alcohol dehydrogenase and aldehyde dehydrogenase variants. Alcohol Res Health 30, 5-13 (2007).

21. Larson, H. N., Weiner, H. \& Hurley, T. D. Disruption of the coenzyme binding site and dimer interface revealed in the crystal structure of mitochondrial aldehyde dehydrogenase "Asian" variant. J Biol Chem 280, 30550-30556, https://doi.org/10.1074/jbc. M502345200 (2005).

22. Chiang, C.P. et al. Ethanol-metabolizing activities and isozyme protein contents of alcohol and aldehyde dehydrogenases in human liver: phenotypic traits of the ADH1B*2 and ALDH2*2 variant gene alleles. Pharmacogenet Genomics, https://doi.org/10.1097/ fpc.0000000000000205 (2016).

23. Harada, S., Agarwal, D. P., Goedde, H. W. \& Ishikawa, B. Aldehyde dehydrogenase isozyme variation and alcoholism in Japan. Pharmacol Biochem Behav 18(Suppl 1), 151-153 (1983).

24. Crabb, D. W., Edenberg, H. J., Bosron, W. F. \& Li, T. K. Genotypes for aldehyde dehydrogenase deficiency and alcohol sensitivity. The inactive ALDH2(2) allele is dominant. J Clin Invest 83, 314-316, https://doi.org/10.1172/jci113875 (1989).

25. Chang, Y. C. et al. Common ALDH2 genetic variants predict development of hypertension in the SAPPHIRe prospective cohort: gene-environmental interaction with alcohol consumption. BMC Cardiovasc Disord 12, 58, https://doi.org/10.1186/1471-2261-12$58(2012)$.

26. Hu, N., Zhang, Y., Nair, S., Culver, B. W. \& Ren, J. Contribution of ALDH2 polymorphism to alcoholism-associated hypertension. Recent Pat Endocr Metab Immune Drug Discov 8, 180-185 (2014).

27. Dickson, P. A. et al. Effects of variation at the ALDH2 locus on alcohol metabolism, sensitivity, consumption, and dependence in Europeans. Alcohol Clin Exp Res 30, 1093-1100, https://doi.org/10.1111/j.1530-0277.2006.00128.x (2006).

28. Cho, Y. et al. Exploring the utility of alcohol flushing as an instrumental variable for alcohol intake in Koreans. Sci Rep 8, 458, https:// doi.org/10.1038/s41598-017-18856-z (2018).

29. Au Yeung, S. L. et al. Is aldehyde dehydrogenase 2 a credible genetic instrument for alcohol use in Mendelian randomization analysis in Southern Chinese men? Int J Epidemiol 42, 318-328, https://doi.org/10.1093/ije/dys221 (2013).

30. Eng, M. Y., Luczak, S. E. \& Wall, T. L. ALDH2, ADH1B, and ADH1C genotypes in Asians: a literature review. Alcohol Res Health 30, 22-27 (2007).

31. Rao, V. R. et al. Single nucleotide polymorphisms in alcohol dehydrogenase genes among some Indian populations. Am J Hum Biol 19, 338-344, https://doi.org/10.1002/ajhb.20589 (2007).

32. Polimanti, R. \& Gelernter, J. ADH1B: From alcoholism, natural selection, and cancer to the human phenome. Am J Med Genet B 177, 113-125, https://doi.org/10.1002/ajmg.b.32523 (2018).

33. Pathak, H. et al. Promoter Polymorphism rs886205 Genotype Interacts With DNA Methylation of the ALDH2 Regulatory Region in Alcohol Dependence. Alcohol Alcohol 52, 269-276, https://doi.org/10.1093/alcalc/agw106 (2017).

34. Dawson, D. A. Defining risk drinking. Alcohol Res Health 34, 144-156 (2011).

35. Schoenborn, C. A. \& Adams, P. E. Health behaviors of adults: United States,2005-2007. Vital Health Stat 10, 1-132 (2010).

36. Shi, Y. Y. \& He, L. SHEsis, a powerful software platform for analyses of linkage disequilibrium, haplotype construction, and genetic association at polymorphism loci. Cell research 15, 97-98, https://doi.org/10.1038/sj.cr.7290272 (2005).

\section{Acknowledgements}

The authors thank the participants in this study for their valuable contributions. This study was supported by the Chang Gung Medical Foundation, Taiwan (grant numbers CMRPG3E1502, CMRPG3H1831, CMRPG3G0962, CMRPG3F1841, and CMRPG3J0931), as well as by the Ministry of Science and Technology, Executive Yuan, Taiwan (grant numbers MOST108-2314-B-182A-047 and MOST108-2629-B-182A-005). 


\section{Author contributions}

Conceived the study: Y.C.C. Designed the experiments: Y.C.C. and Y.S.L. Performed the laboratory work: Y.C.C., Y.S.L., K.H.C. and C.M.C. Analyzed and interpretation of data: Y.H.H. and Y.S.L. Wrote the first draft of manuscript: Y.H.H. and K.H.C. Wrote and revised the final version of manuscript: Y.H.H. and Y.C.C.

\section{Competing interests}

The authors declare no competing interests.

\section{Additional information}

Supplementary information is available for this paper at https://doi.org/10.1038/s41598-020-60567-5.

Correspondence and requests for materials should be addressed to Y.-C.C.

Reprints and permissions information is available at www.nature.com/reprints.

Publisher's note Springer Nature remains neutral with regard to jurisdictional claims in published maps and institutional affiliations.

(c) (i) Open Access This article is licensed under a Creative Commons Attribution 4.0 International License, which permits use, sharing, adaptation, distribution and reproduction in any medium or format, as long as you give appropriate credit to the original author(s) and the source, provide a link to the Creative Commons license, and indicate if changes were made. The images or other third party material in this article are included in the article's Creative Commons license, unless indicated otherwise in a credit line to the material. If material is not included in the article's Creative Commons license and your intended use is not permitted by statutory regulation or exceeds the permitted use, you will need to obtain permission directly from the copyright holder. To view a copy of this license, visit http://creativecommons.org/licenses/by/4.0/.

(C) The Author(s) 2020 